\title{
A APLICABILIDADE DA AGENDA DE TRABALHO DECENTE PARA PROTEÇÃO DO TRABALHADOR MIGRANTE NO BRASIL
}

\section{Priscila Cavalcanti Côrtes1 \\ Luciana Aboim Machado Gonçalves da Silva2}

\section{RESUMO}

O presente estudo busca analisar as perspectivas atuais para a implementação de condições dignas de trabalho para os migrantes no Brasil, que chegam ao país de forma marginalizada, necessitando de acolhimento por parte das instituições públicas a fim de que se respeitem seus Direitos Fundamentais. A análise tomará como ponto de partida a Agenda de Trabalho Decente promovida pela Organização Internacional do Trabalho e seus impactos no Brasil.

Palavras-chave: Direito do Trabalho. Migrante. Agenda de Trabalho Decente. OIT.

\section{THE APPLICABILITY OF THE DECENT WORK AGENDA TO PROTECT MIGRANT WORKER IN BRAZIL}

\section{Abstract}

The present study seeks to analyze the current perspectives for the implementation of decent working conditions for migrants in Brazil, who come to the country in a marginalized way, requiring the reception of public institutions in order to respect their Fundamental Rights. The analysis will take as its starting point the Decent Work Agenda promoted by the International Labor Organization and its impacts on Brazil.

Keywords: Labor law. Migrant. Decent Work Agenda. ILO

\section{INTRODUÇÃO}

A promoção do trabalho decente passou a ser uma preocupação no Brasil principalmente após o compromisso assumido em junho/2003 pelo Governo brasileiro junto à Organização Internacional do Trabalho de elaboração de programa especial que envolvesse

\footnotetext{
${ }^{1}$ Servidora Pública Federal. Mestranda pela UNIVERSIDADE FEDERAL DE SERGIPE. Pós graduada em Direito e Processo do Trabalho pela Faculdade Estácio de Sá e em Direitos Humanos e Ressocialização pela Faculdade Única.

${ }^{2}$ Pós-doutora em Direito pela Universidade Federal da Bahia e pela Università Degli Studi G. d'Annunzio (Itália). Doutora em Direito do Trabalho pela Faculdade de Direito da Universidade de São Paulo. Mestre em Direito do Trabalho, Especialista em Direito do Trabalho e em Direito Processual Civil, todos pela Pontifícia Universidade Católica de São Paulo. Professora Associada da graduação em Direito e do Programa de PósGraduação "Stricto Sensu" em Direito e Vice-Coordenadora da graduação em Direito da Universidade Federal de Sergipe. Coordenadora do Programa de Pós-Graduação em Direito - PRODIR da Universidade Federal de Sergipe. Vice-Presidente da Asociación Iberoamericana de Derecho del Trabajo y de la Seguridad Social "Guillermo Cabanellas". Membro do Instituto Ítalo-Brasileiro de Direito do Trabalho.
} 
não só o Estado, mas também empregados e empregadores na busca da implementação efetiva da dignidade da pessoa humana nas relações trabalhistas.

A preocupação com o trabalho decente decorre do fato de que este é condição sine qua non para o desenvolvimento de uma sociedade, superando a pobreza e ampliando a igualdade social.

Para esse trabalho será utilizado o "trabalho decente" como aquele que é remunerado adequadamente, é realizado em condições de salubridade, segurança e liberdade, que seja suficiente para garantir uma vida digna ao trabalhador e à sua família. Seguirá, portanto, a linha de pesquisa relativa ao Direito do Trabalho e Meio Ambiente do Trabalho, ao refletir sobre a proteção legal de minorias, como os trabalhadores migrantes.

$\mathrm{O}$ artigo é dividido em três partes principais, sendo a primeira a tratar da preocupação internacional com a promoção do trabalho decente, a exemplo da Agenda 2030 da ONU e de que forma isto foi trazido para o âmbito jurídico interno brasileiro.

Em um segundo momento é feita uma abordagem sobre o trabalho do migrante no Brasil, com distinções terminológicas iniciais, pretende-se traçar um panorama atual das condições trabalhistas desses indivíduos.

Já na terceira etapa, será abordada a possibilidade de aplicação das medidas sugeridas na Agenda Nacional de Trabalho Decente ao migrante trabalhador no Brasil.

Sob este viés analítico procuraremos responder ao seguinte problema: É possível a inclusão do trabalhador migrante na Agenda Nacional de Trabalho Decente?

A metodologia utilizada foi o levantamento bibliográfico e levantamento documental. A problemática da pesquisa é buscar caminhos para a aplicação da Agenda Nacional de Trabalho Decente também aos migrantes que chegam ao Brasil em busca de condições mais dignas de existência, com uma vertente metodológica jurídica-sociológica que a profundidade do tema impõe.

\section{A INTERNALIZAÇÃO DA PREOCUPAÇÃO COM A EFETIVAÇÃO DO} TRABALHO DECENTE

A comunidade internacional tem somado esforços para o alcance do trabalho decente, podendo se destacar tanto a Conferência Regional de Emprego do Mercosul, ocorrida em Buenos Aires, em abril de 2004, bem como a Assembleia Geral das Nações Unidas 
(ONU) ocorrida em Nova York em 2005, na qual constou em sua Resolução final os seguintes termos:

\begin{abstract}
Apoiamos firmemente uma globalização justa e resolvemos fazer com que os objetivos do emprego pleno e produtivo e o trabalho decente para todos, especialmente para as mulheres e os jovens, sejam uma meta fundamental das nossas políticas nacionais e internacionais e de nossas estratégias nacionais de desenvolvimento, incluindo as estratégias de redução da pobreza, como parte de nossos esforços para atingir os Objetivos de Desenvolvimento do Milênio.(ONU, 2005)
\end{abstract}

Para a Organização Internacional do Trabalho (OIT), por seu turno, a promoção do trabalho decente se embasa em quatro pilares estratégicos:
a) respeito às normas internacionais do trabalho, em especial aos princípios $e$ direitos fundamentais do trabalho (liberdade sindical e reconhecimento efetivo do direito de negociação coletiva; eliminação de todas as formas de trabalho forçado; abolição efetiva do trabalho infantil; eliminação de todas as formas de discriminação em matéria de emprego e ocupação);
b) promoção do emprego de qualidade;
c) extensão da proteção social;
d) diálogo social. (OIT, 2006)

Desse modo, a chamada Agenda 2030 da ONU incluiu como o oitavo objetivo o “Trabalho Decente e Crescimento Econômico", denotando a importância internacionalmente reconhecida da promoção da dignidade da pessoa humana dentro do trabalho.

A Agenda 2030 é o plano de ação global proposto pela ONU para um desenvolvimento sustentável assinada em Nova York em 2015 por 193 Estados-membros.

Em âmbito internacional, a comunidade jurídica discute inclusive sobre os direitos adquiridos dos indivíduos migrantes em face de tantas modificações no cenário jurídico e econômico ultimamente.

Essa discussão foi muito bem abordada por Christa Tobler:

At the present, ir is the perspective of "Brexit" that raises the issue of the protection of acquired rights in a concrete context. When preparing for negotiations on the withdrawal agreement, the UK will do well to remember the examples discussed in this contribution. Like in Switzerland, persons who have already been risiding more than five years in their host country will normally enjoy this right as a matter of nation law. For other, however, an agreement containing a specific provision on the protection of acquired rights will be needed. ${ }^{3}$ (TOBLER, 2017)

Toda essa preocupação internacional não poderia deixar de impactar o Brasil, especialmente considerando o contexto globalizado em que estamos inseridos. Assim, em

3 Em livre tradução "No presente, vai a perspectiva do "Brexit" que levanta a questão da proteção dos direitos adquiridos em um contexto concreto. Ao se preparar para negociações sobre o acordo de retirada, o Reino Unido fará bem em lembrar os exemplos discutidos nesta contribuição. Como na Suíça, as pessoas que riem há mais de cinco anos em seu país de acolhimento normalmente desfrutam desse direito como uma questão de lei nacional. Para outros, no entanto, será necessário um acordo que contenha uma disposição específica sobre a proteção dos direitos adquiridos." 
terras brasileiras, o compromisso de implementar um trabalho decente a todos teve seu embrião, como citado na introdução deste trabalho, com a assinatura em junho de 2003 pelo então Presidente da República de um Memorando de Entendimento que previa um Programa Especial de Cooperação Técnica a fim de que houvesse efetiva promoção de uma Agenda Nacional de Trabalho decente, que envolvesse a participação de toda a sociedade.

No referido memorando foram definidas quatro áreas com prioridade de atuação, que seriam, em suma:

a) geração de emprego, microfinanças e capacitação de recursos humanos, com ênfase na empregabilidade dos jovens;

b) viabilização e ampliação do sistema de seguridade social;

c) fortalecimento do tripartismo e do diálogo social;

d) combate ao trabalho infantil e à exploração sexual de crianças e adolescentes, ao trabalho forçado e à discriminação no emprego e na ocupação. (MINISTÉRIO DO TRABALHO E EMPREGO, 2010)

Definidas as áreas de atuação e a forma de coordenação pelo extinto Ministério do Trabalho e emprego, foi lançada, em 2006, durante a XVI Reunião Regional Americana da OIT, ocorrida em Brasília, a chamada Agenda Nacional de Trabalho Decente (ANTD),que passou a ser incluída inclusive no Plano Plurianual de 2004-2007.

A atuação incluída na referida Agenda, então, passou a ter prioridades traçadas como a geração de mais e melhores empregos, sem perder de vista a igualdade de oportunidade e de tratamento entre os trabalhadores; como a erradicação integral da escravidão moderna e a eliminação da exploração de trabalho infantil; e como o fortalecimento do tripé trabalhista (governo, empregado e empregador) e do diálogo social entre esses atores, a fim de se alcançar uma governabilidade democrática.

Os mecanismos pensados na ANTD para a sua implementação se embasaram principalmente a partir desse intersecção entre as entidades de classe e o Governo brasileiro, com implementação de uma cooperação técnica interna além de uma Cooperação Sul-Sul entre países da América Latina e da África, onde há a promoção de trocas de experiências entre os Estados com difusão de boas práticas que trouxeram bons resultados em cada local.

Reflexos podem ser observados em alguns Estados da federação brasileira. Tomese como exemplo o Estado da Bahia que lançou, junto à sua Secretaria do Trabalho, Emprego, 
Renda e Esporte, em 2007, a Agenda Bahia do Trabalho Decente ${ }^{4}$. Esta iniciativa pioneira, foi a primeira agenda subnacional de trabalho decente desenvolvida no mundo.

Naquele Estado, foram definidos nove eixos de atuação governamental para promoção do trabalho decente: Erradicação do Trabalho Escravo; Erradicação do Trabalho Infantil; Segurança e Saúde do Trabalhador; Promoção da Igualdade da Pessoa com Deficiência; Promoção da Igualdade de Gênero e Raça; Serviço Público; Juventude; Trabalho Doméstico; Empregos Verdes.

Mister notar que dentre os nove pontos de atuação, não mereceram atenção a situação dos migrantes.

$\mathrm{Na}$ mesma esteira seguiu o Estado de Minas Gerais quando criou a "Agenda mineira do Trabalho Decente"

A referida agenda subnacional visa à implementação de políticas dentro do meio ambiente do trabalho no Estado que promova a mobilização dos atores laborais na busca de condições mais dignas para todos. Esta proposta também não incluiu o migrante em sua proteção.

Fica claro, portanto, que embora tenham havido esforços no Brasil para concretização de uma Agenda em prol do trabalho decente, o migrante não é sujeito prioritário dos direitos garantidos ou das políticas públicas formuladas.

\section{A SITUAÇÃO DO TRABALHADOR MIGRANTE NO BRASIL}

Inicialmente, ante a confusão comumente realizada entre os termos, é necessário uma breve diferenciação entre o que se entende por "migrante" e por "refugiado", uma vez que a utilização das palavras deve ser acurada, para não gerar controvérsias.

Em outra oportunidade assim traçamos essa distinção terminológica:

(...) Dunque, immigrante è l'individuo che entra in un paese con intenzione di vivere in esso; già, il termine emigrante è usato per riferirsi a qui lascia il suo paese per vivere altrove.

Altrimenti, l'espressione migrante ha il significato di ogni persona che si trasferisce da un altro luogo all'interno del paese o al di là dei suoi confini. Questa terminologia è più ampia e, quindi, appropriata.

(...) 
Anche è importante avere attenzione al vocabolo rifugiato che - a differenza di migrante - concerne la persona che si adatta alla definizione della Convenzione relativa allo Statuto dei Rifugiati (1951) (... $)^{6}$ (SILVA E SILVA NETO)

Assim fica claro que os termos "migrante' e "refugiado" não são sinônimos, estando o refugiado coberto por um grande número de convenções internacionais em virtude de sua saída do seu país natal ter sido causada por perseguições, conflitos internos, fugindo da violência de seu local de origem.

Ante as situações perigosas enfrentadas, os refugiados estão numa posição muito mais frágil e marginalizada, sendo acolhidos por entidades internacionais como a Agência da ONU para Refugiados (ACNUR).

Por outro lado, quanto ao migrante, embora não exista uma definição precisa em textos internacionais, convencionou-se em utilizar-se esse termo como aquele indivíduo que chega a um novo país fruto de um processo voluntário, quando alguém cruza as fronteiras em busca de melhores condições de vida, mas mantendo seus direitos em seu país de origem.

Estabelecidos os conceitos utilizados, precisamos adentrar na situação em que se encontra o trabalhador migrante no Brasil, uma vez que estes chegam ao país muitas vezes em condições marginalizadas buscando condições mais dignas de existência.

Segundo dados estatísticos do Observatório das Migrações Internacionais, órgão vinculado ao extinto Ministério do Trabalho, publicados no último relatório anual divulgado em 2018, houve aumento no número de autorizações para trabalho de migrantes concedidas pela Coordenação Geral de Imigração (CGIg).

Além dessas autorizações concedidas antes mesmo do ingresso do migrante no território brasileiro, com as modificações perpetradas pela Lei ${ }^{\circ} 13.445 / 2017$, possibilitou-se a concessão de autorizações mesmo após o ingresso no Brasil. Nesse sentido conclui o relatório:

Outra característica que podemos observar é que as autorizações de trabalho concedidas para imigrantes se concentram em dois níveis educacionais. O primeiro seria de superior completo e, portanto, são imigrantes com alto nível de formação profissional e o segundo seriam de imigrantes com nível médio completo, que já não

${ }^{6}$ Em livre tradução: (...) Portanto, um imigrante é o indivíduo que entra em um país com a intenção de viver nele; já, o termo emigrante é usado para se referir aqui, ele deixa seu país para viver em outro lugar.

Caso contrário, a expressão migrante tem o significado de cada pessoa que se desloca de outro lugar dentro do país ou além de suas fronteiras. Essa terminologia é mais ampla e, portanto, apropriada.

(...)

É também importante prestar atenção à palavra refugiada que, ao contrário dos migrantes, diz respeito à pessoa que se adapta à definição da Convenção relativa ao Estatuto dos Refugiados (1951) (...) 
seriam com um nível de formação tão alto. Os imigrantes com nível superior completo são principalmente os nacionais dos EUA, Filipinas, França e Reino Unido. Já os imigrantes de nível médio completo são imigrantes originários dos seguintes países EUA, Reino Unido, China, e Itália. (OBMigra, 2018)

Esses números, porém, embora sejam importantes para traçar um quadro geral das migrações no Brasil, apenas reflete aqueles indivíduos que têm sua situação formal regularizada. Isso pode ser observado a partir do sensivelmente elevado nível de escolaridade daqueles solicitantes, como atestou o relatório.

Dentro da cifra oculta encontram-se os migrantes em situação irregular, que consequentemente não conseguem pedir autorização para o trabalho.

A realidade para estes é ainda mais severa, a informalidade na sua situação imigratória acaba marginalizando ainda mais os trabalhadores que se submetem a condições absolutamente indignas e análogas à de escravos para garantir a sua sobrevivência e sob constantes ameaças de denúncias às autoridades de sua informalidade e receio de deportação.

Como bem retratado por Brito (2002), o meio ambiente do trabalho é o local propício para discriminações e abusos, em que o capital do empregador mostra o seu poder de reprimir o trabalhador que necessita da sobrevivência, sujeitando-se a todos os tipos de torpeza por não lhe restarem outras alternativas.

Assim, para o autor, na relação de emprego:

(...) encontra-se a condição ideal para quem vai discriminar: o fato de que nela existe, via de regra, a sujeição de um homem pelo outro, decorrentes das necessidades do primeiro de trabalhar e com isso garantir sua sobrevivência e de sua família. (BRITO, 2002)

Nesse diapasão, leciona Bauman, citado por Timóteo (2011) que:

na sociedade atual, laços e parcerias tendem a ser vistos e tratados como coisas destinadas a serem consumidas, e não produzidas; estão sujeitos aos mesmos critérios de avaliação de todos os outros objetos de consumo (2001: 187). Quando o outro é visto como bem a ser consumido nas relações sociais, fica muito mais fácil desconsiderar todas as suas dimensões humanas. No caso da força de trabalho, é possível enxergá-la como um composto de objetos, de instrumentos e não de pessoas. Dentro dessa lógica, portanto, há poucos obstáculos para se dar um passo adiante e tratar o trabalhador como objeto descartável.

Com efeito resta evidente a urgência na busca de efetivação da dignidade da pessoa humana nas relações trabalhistas, em especial quando em um dos pólos se encontram seres humanos hipervulneráveis, como os migrantes.

Para tanto, Brito (2016) conclui que um trabalho decente, no âmbito individual, perpassa não apenas pela garantia de acesso ao trabalho, mas principalmente pela 
concretização de liberdade de escolha ao trabalho, de igualdade de oportunidades de acesso ao trabalho e dentro do meio ambiente laboral, pela observância do direito de exercer o trabalho em condições que preservem a saúde do trabalhador, pelo respeito ao direito a uma justa remuneração, pela concretização do direito a justas condições laborais, especialmente quanto à limitação da jornada e respeito aos períodos de repouso, e pela proibição de trabalho infantil.

Todas essas condições mínimas devem ser cumpridas para que se alcance um trabalho verdadeiramente decente, em especial quando se trata do trabalhador migrante.

Seja pela falta de documentação, ou pela inacessibilidade dos meios formais de regularização, os migrantes acabam incluídos em um contexto de exploração indigna, com submissão a condições insalubres e perigosas, como sweating system e fazendas com trabalhos extenuantes.

Os migrantes, em especial aqueles em condição formal irregular, são, portanto alvos notáveis para a escravidão moderna, mal que aflige o mundo contemporâneo e do qual o Brasil não escapa ileso.

Em outra oportunidade, pudemos aduzir que:

De acordo com o ordenamento jurídico pátrio, tem-se o art. $5^{\circ}$, incisos III e XLVII da Constituição Federal que veda o tratamento desumano ou degradante e estabelece a proibição de trabalhos forçados.

o Código Penal Brasileiro reprime o crime de redução da pessoa à condição análoga à de escravo no art. 149, alterado pela Lei 10.803/2003. Assim, esse dispositivo criminaliza as práticas de trabalhos forçados, cerceamento da liberdade por isolamento geográfico ou dívida, trabalho com jornadas exaustivas e condições degradantes por considerá-las maneiras de reduzir o indivíduo a condição análoga à de escravo. (SILVA E BRITTO, 2019)

Na mesma esteira, Vanessa Rodriguez (2013) também compreende que:

Resulta necesario recordar que es el status o condición de una persona sobre la cual se ejerce todo o alguno de los poderes associados al derecho de propriedade; y la servidumbre es la sujecíon de una persona bajo la autoridad de otra con subordinación a la voluntad y los designios de otra sin que tenga opción a decidir, protestar o discrepar, con la total perdida de la libertad y con la consecuente despersonalización y captación de voluntad. (RODRÍGUEZ, 2013, p. 82).

Assim, o migrante necessita de políticas públicas com forte atuação estatal para que lhe sejam garantidas condições dignas de trabalho e de vida, independente da regularização da sua situação formal junto aos órgãos imigratórios.

Uma das propostas para o enfrentamento da marginalização desse grupo social é a aplicação das práticas previstas na Agenda Nacional de Trabalho Decente. 


\section{APLICAÇÃO dAS PRÁtiCAS PROPOSTAS NA AGENDA NACIONAL} DE TRABALHO DECENTE AOS MIGRANTES NO BRASIL

A Agenda Nacional de Trabalho Decente firmada pelo Brasil ${ }^{7}$ apenas tangencia a condição digna de trabalho do migrante no país quando aponta, dentro do plano de extensão da proteção social, que deve-se buscar a melhoria das condições de trabalho dos trabalhadores migrantes.

Ocorre que essa previsão é eminentemente superficial, carecendo de maior atenção e profundidade para a questão do migrante em território nacional, já que são vítimas em potencial de exploração, sendo na prática mão-de-obra barata, necessitando de políticas públicas voltadas à sua proteção.

Em verdade, no nosso sistema jurídico e econômico atual há uma maior suscetibilidade de exploração do trabalhador migrante no Brasil ante a vulnerabilidade a que estão sujeitos esses indivíduos.

Pode-se destacar que a situação do migrante que chega ao Brasil obteve uma recente melhora a partir da publicação da nova lei de migrações, Lei $n^{\circ}$ 13.445/2017, que substituiu o antigo Estatuto do Estrangeiro.

Contudo, estas alterações não foram suficiente para garantir, na prática, uma realidade de respeito às garantias fundamentais do indivíduo.

Dentro do panorama nacional, em busca da diminuição da exposição às mazelas sociais a que estão expostos os migrantes, pode-se procurar abrigo nos Direitos Fundamentais garantidos pela Constituição.

No entanto, uma leitura superficial da Lei Maior de 1988 pode levar a uma conclusão equivocada do entendimento do legislador constituinte quanto aos sujeitos de direitos destinatários da proteção constitucional, uma vez que o texto, no art. $5^{\circ}$, limita-se a conferir proteção dos estrangeiros aqui residentes.

A hermenêutica, portanto, não pode ser literal, a fim de que não se torne excludente e fonte de preconceitos embasados em formalismo gramatical, já que a universalidade dos Direitos Fundamentais deve levar o intérprete à conclusão pautada sempre pelo lado de maior aplicação e concretização do conteúdo constitucional.

7 A Agenda Nacional pode ser encontrada no sítio eletrônico da Organização Internacional do Trabalho: https://www.ilo.org/wcmsp5/groups/public/---americas/---ro-lima/---ilobrasilia/documents/publication/wcms_226229.pdf 
Nessa esteira, aponta Adolfo Mamoru Nishiyama (2004):

Os direitos fundamentais visam à ampla proteção do ser humano (nacional ou estrangeiro), tanto é que referida norma prega que 'todos são iguais perante a lei, sem distinção de qualquer natureza'. Assim, os estrangeiros que estão em passagem pelo território nacional são também destinatários dos direitos fundamentais, uma vez que entram em contato com o ordenamento jurídico brasileiro.

Ou seja, considerando que é desígnio próprio dos direitos fundamentais a proteção abrangente do ser humano como um todo, este acolhimento não pode por consequência lógica excluir deliberadamente uma classe de pessoas em virtude do seu país de origem.

Logo, estão salva-guardados os direitos mesmo daqueles estrangeiros que não pretendam estabelecer sua residência no Brasil. Esta conclusão nada mais é que um consectário da dignidade da pessoa humana, que não faz distinções de quaisquer espécies, inclusive de nacionalidade.

Cumpre ressaltar, conforme ensinamentos de André Ramos Tavares (2006), que o próprio art. $5^{\circ}$ da CRFB atribui direitos fundamentais sem distinção de nacionalidade quando trata de igualdade entre homens e mulheres (art. $\left.5^{\circ}, \mathrm{I}\right)$, quando genericamente utiliza o termo "ninguém" (art. 5\%, incisos III, VIII, XX, LIII, LIV, LXI, e LXVI), quando faz uso da palavra "todos" (art. 5', incisos XIV, XVI, XXXIII, XXXIV e LXXVIII) e mesmo "qualquer pessoa" (art. $5^{\circ}$, LXII), o que denota a falta de técnica do constituinte ao tratar do tema.

Assim também é o entendimento da Corte Suprema brasileira, que já reconheceu o estrangeiro, independente de sua condição de residente ou não, como titular de Direitos Fundamentais:

Cumpre reconhecer, desde logo, por necessário, que o fato de o paciente ostentar a condição jurídica de estrangeiro e de não possuir domicílio no Brasil não lhe inibe, só por si, o acesso aos instrumentos processuais de tutela da liberdade nem lhe subtrai, por tais razões, o direito de ver respeitadas, pelo Poder Público, as prerrogativas de ordem jurídica e as garantias de indole constitucional que o ordenamento positivo brasileiro confere e assegura a qualquer pessoa que sofra persecução penal instaurada pelo Estado. ${ }^{8}$

Outra não poderia ser a conclusão, senão a inclusão dos migrantes como sujeitos de direitos fundamentais previstos na Constituição brasileira de 1988, em especial atentandose aos termos do art. $3^{\circ}$, IV que dispõe ser objetivo fundamental da República Federativa do Brasil a promoção do bem de todos, sem preconceitos de origem, raça, sexo, cor, idade e quaisquer outras formas de discriminação.

8 (STF, HC 94016 MC/SP, rel. Min. Celso de Mello, j. 7/4/2008) 
Desse modo, não poderia o aplicador do direito restringir o alcance da norma constitucional violando o dever de promover o bem de todos, sem distinção de país de origem.

Assim, ressalvadas as exceções expressamente consignadas na Constituição Federal, a exemplo do art. $12, \S 3^{\circ}$ o qual determina exclusividade para brasileiros natos de certos cargos de importância estratégica para a soberania nacional, bem como a exemplo do art. 5', LI que trata de regras gerais sobre a extradição, não é admissível nenhuma discriminação decorrente do país de origem do indivíduo

Já pudemos também tratar sobre a ampla abrangência do conceito de estrangeiro incluído na Constituição Federal em outra obra quando concluímos: "Posto isso, não restam dúvidas de que os estrangeiros não-residentes no Brasil gozam de direitos fundamentais, salvo quando expressamente o texto constitucional restringir a titularidade ativa do direito fundamental." (SILVA, 2006).

Logo, a melhoria das condições de trabalho também é um compromisso que abrange igualmente os estrangeiros migrantes, quer estejam em situação formal regular ou irregular, quer sejam ou não residentes no país.

Reforça essa conclusão a aplicabilidade horizontal e vertical dos Direitos Fundamentais que implica a incidência de direitos fundamentais garantidos constitucionalmente dentro de relações particulares horizontais ou mesmo em relações trabalhistas em que há hipossuficiência em uma das partes, embora seja uma relação privada.

A esse respeito, é a clássica lição primorosa de Tomás Quadra-Salcedo (1981):

la obligación de respectar los derechos fundamentales por los ciudadanos surge y emana directamente de la Constitución y no sólo de las normas de desarrollo de ésta, no es por lo tanto un mero reflejo del ordenamiento que puede sufrir las alteraciones, modificaciones y supresiones que el legislador decida, sino que hay un núcleo esencial que se deduce directamente de la Constitución y que se impone a todos los ciudadanos. ${ }^{9}$

Esta vinculação direta dos Direitos Fundamentais nas relações entre particulares, incluindo os trabalhadores migrantes, se deve, principalmente, na opinião de Ingo Wolfgang Sarlet (2005), em decorrência de previsão expressa de aplicabilidade imediata das normas definidoras de garantias fundamentais do art. $5^{\circ}, \S 1^{\circ}$ da nossa Constituição.

${ }^{9}$ Em livre tradução: “A obrigação de respeitar os direitos fundamentais pelos cidadãos surge e emana diretamente da Constituição e não apenas das normas de seu desenvolvimento, não é, portanto, um mero reflexo da ordem que pode sofrer as alterações, modificações e exclusões que o legislador decidir, mas há um núcleo essencial que segue diretamente da Constituição e é imposto a todos os cidadãos." 
O mesmo autor ainda relembra que a forma que se dá a aplicação dos direitos fundamentais às relações privadas não é uniforme, necessitando de maior análise do caso concreto. Ele ainda sustenta que o fundamento maior para a eficácia direta é encontrado no princípio da dignidade da pessoa humana, previsto no art. $1^{\circ}$, III, CRFB.

Todos esses argumentos devem ser levados em consideração para se concluir pela incidência dos direitos e garantias fundamentais insculpidos na Constituição Federal diretamente nas relações trabalhistas.

Se estes incidem em relações trabalhistas comuns, com muito mais razão a aplicabilidade deve ser garantida para relações trabalhistas que contem com uma parte hipervulnerável, tais como são os migrantes.

Sensíveis com a temática, alguns entes da Federação, então, buscaram efetivar mecanismos de concretização da Agenda Nacional de Trabalho Decente em face dos migrantes.

Pode-se citar a iniciativa positiva da cidade de São Paulo que, no bojo de sua Secretaria Municipal de Direitos Humanos e Cidadania, a partir do art. 242 da Lei Municipal $\mathrm{n}^{\mathrm{o}}$ 15.764/13 criou a Coordenação de Políticas para Imigrantes e Promoção do Trabalho Decente $e^{10}$.

A cidade de São Paulo é um dos principais centros urbanos no Brasil de concentração de imigrantes advindos de outros países. Esse fato decorre principalmente da visibilidade internacional que a cidade tem, alimentando ilusões de que vê de fora de que será o lugar ideal para recomeçar a vida com grandes oportunidades profissionais.

A realidade dos migrantes que chegam ao Brasil e a São Paulo, no entanto, é bastante diferente.

Empurrados à margem da sociedade, com barreiras linguísticas, sem dinheiro, com a situação formal irregular, estes migrantes são relegados a postos de trabalho indignos, considerados análogos a de escravos.

A chamada escravidão moderna, com utilização de mão de obra dos imigrantes no Brasil já foi relatada por Illes, Timóteo e Pereira (2008) quando afirmaram:

O trabalho escravo é, sobretudo, conseqüencia de um sistema complexo, no qual está presente a desigualdade social, a falta de oportunidades, a vulnerabilidade social, a falta de políticas sociais, o subdesenvolvimento econômico, a rede de

10 $\mathrm{p}=274405$ 
tráfico de pessoas, os entraves jurídicos que dificultam a legal permanência e regularização do trabalhador imigrante etc. $O$ imigrante latino-americano indocumentado que trabalha no setor de costura no Brasil tem seus direitos humanos sistematicamente violados. Dezenas de reportagens foram realizadas buscando denunciar as condições enfrentadas por esses trabalhadores. Traços recorrentes nas caracterizações jornalísticas são jornadas exaustivas de até 18 horas; salários inferiores ao mínimo; má alimentação; retenção de documentos; cerceamento do direito de ir e vir por meio de portas trancadas elou câmeras de vigilância; descontos nos pagamentos relativos a despesas com alimentação, moradia e viagem Bolívia-Brasil; condições insalubres, como pouca luminosidade, deficiência de instalações sanitárias e de moradia

Conforme aponta Patussi (2005), citado pelos mesmos autores:

A grande maioria dos bolivianos trabalha e mora no mesmo local insalubre onde estão instaladas as oficinas de costura, o que traz sérios problemas para a saúde. Um dos mais graves é a tuberculose. Uma jornada normal, no ramo da costura, é de 12 a 14 horas diárias, mas muitos trabalham das 7 h̀ 0 h. Um imigrante que não quis se identificar declarou: "eu não podia reclamar, não podia fazer valerem os meus direitos porque eu pensava que não tinha nenhum. Eu não tinha documento aqui”".

Logo, é de suma importância o trabalho da coordenadoria do município que visa à articulação de políticas públicas voltadas à proteção dos migrantes, uma vez que a cidade de São Paulo é grande polo de chegada de estrangeiros que se dirigem ao Brasil na ilusão de melhoria da qualidade de vida mediante promessas de empregos, os quais quase nunca se concretizam.

O trabalho se dá com a inserção social dos imigrantes de forma transversal, intersetorial e participativa, com a promoção de ações governamentais que tragam estes indivíduos para a luz da dignidade.

A referida Coordenadoria atua em várias frentes com projetos que buscam a integração dos imigrantes à sociedade, seja através da promoção da facilitação da regularização de sua situação formal, com a possibilidade de abertura de contas bancárias, ou através da criação de abrigo emergencial para acolhimento dessas pessoas, ou mesmo mediante a implementação de curso gratuito de português, dentre outras iniciativas.

Há o trabalho também de conscientização da população quanto à xenofobia e seus malefícios, bem como com a preparação dos servidores públicos voltados ao atendimento dessa grupo social.

Assim, pode-se concluir que tanto em âmbito internacional, quanto dentro do Brasil, há uma preocupação com a garantia de Direitos Fundamentais do migrante, aqui incluída a promoção da Agenda Nacional de Trabalho Decente. 
A Agenda traz importantes marcos para fixar ações em direção ao meio ambiente de trabalho digno e gerou frutos nos Estados e, especialmente, na cidade de São Paulo que transformou a meta de fomentação do trabalho decente em uma meta de acolhimento dos trabalhadores migrantes, criando condições de inserção desses indivíduos na sociedade, cumprindo verdadeiramente o objetivo fundamental da República de construção de uma sociedade livre, justa e solidária (art. $3^{\circ}$, I, CRFB).

\section{CONCLUSÃO}

Como afirmado ao longo deste trabalho, os migrantes que chegam ao Brasil, saem de seus países em busca de melhores condições de sustento e sobrevivência para si e para sua família.

Ocorre que, muitas vezes, ao chegar ao local de destino, a dura realidade lhes abate. A carência de postos de trabalhos, a dificuldade na regularização de seus documentos e a violência cotidiana, acaba por marginalizá-los ainda mais.

Esta marginalização muitas vezes acarreta a submissão desses seres humanos a trabalhos indignos e perigosos, completamente sem salubridade ou respeito às normas de segurança do trabalho.

Desse modo, fica evidente a urgência em se procurar meios de proteção dessa população hipervulnerável.

A solução tem seu berço, como não poderia deixar de ser, na Lei Maior de 1988. A Constituição Federal traz Direitos e Garantias fundamentais que devem ser aplicadas diretamente nas relações entre particulares. Tais direitos põe a salvo a dignidade da pessoa humana daqueles migrantes, proibindo a submissão destes a situações análogas à de escravos.

A proteção dos direitos dos estrangeiros, independente da sua origem, e residência fixa, foi tratado em decisões pelo Supremo Tribunal Federal.

Como consectário direto do Princípio da dignidade (art. $1^{\circ}$, III, CRFB) e fruto das pressões dos órgãos internacionais, o Brasil publicou sua Agenda Nacional de Trabalho Decente, a qual fixa parâmetros de atuação, envolvendo todos os atores participantes das relações trabalhistas, a fim de implementar o combate ao labor degradante.

Essa Agenda, embora não toque com profundidade o tema do migrante trabalhador no Brasil, não deixa de trazê-lo em seu bojo. 
Aproveitando, então as discussões trazidas pela ADTD, iniciativas como a da cidade de São Paulo, polo de concentração de chegada de muito imigrantes em situação formal irregular, auxilia na promoção do trabalho decente entre esse grupo de pessoas, sendo um modelo a ser seguido por todo o país.

Com efeito, resta respondida a pergunta formulada no início do trabalho. Sim, é possível e, mais do que isso, é urgente e necessária a inclusão dos trabalhadores migrantes na Agenda Nacional de Trabalho Decente no Brasil.

\section{REFERÊNCIAS}

BAUMAN, Zygmunt. Modernidade líquida. Rio de Janeiro: Jorge Zahar, 2001 apud TIMÓTEO, Gabrielle Louise Soares. Os trabalhadores bolivianos em São Paulo: uma abordagem jurídica. Dissertação (Mestrado em Direito). Faculdade de Direito.

Universidade de São Paulo. 2011.

BRITO FILHO, José Claudio Monteiro de. Trabalho Decente: Análise jurídica da exploração do trabalho - Trabalho escravo e outras formas de trabalho indigno. $4^{\mathrm{a}} \mathrm{ed}$. São Paulo: LTr, 2016, p. 51-54.

BRITO FILHO, José Claudio Monteiro de. Discriminação no trabalho. São Paulo: LTr, 2002, p. 43.

CAVAlCANTI, L; OLIVEIRA, T.; MACEDO, M., Migrações e Mercado de Trabalho no Brasil. Relatório Anual 2018. Série Migrações. Observatório das Migrações Internacionais; Ministério do Trabalho/ Conselho Nacional de Imigração e Coordenação Geral de Imigração. Brasília, DF: OBMigra, 2018.

ILLES, Paulo; TIMOTEO, Gabrielle Louise Soares and FIORUCCI, Elaine da Silva. Tráfico de Pessoas para fins de exploração do trabalho na cidade de São Paulo. Cad. Pagu [online]. 2008, n.31, pp.199-217. ISSN 0104-8333. Disponível em: http://www.scielo.br/pdf/cpa/n31/n31a10. Acesso em: 02 ago. 2019.

MINISTÉRIO DO TRABALHO E EMPREGO, Plano Nacional de Trabalho Decente. Brasília, 2010. Disponível em: https://www.ilo.org/wcmsp5/groups/public/---americas/---rolima/---ilo-brasilia/documents/publication/wcms_226249.pdf

NISHIYAMA, Adolfo Mamoru. Remédios constitucionais. São Paulo: Manole, 2004, p. 82.

ORGANIZAÇÃO INTERNACIONAL DO TRABALHO, Agenda Nacional de Trabalho Decente. Brasília, 2006. Disponível em: https://www.ilo.org/wcmsp5/groups/public/--americas/---ro-lima/---ilo-brasilia/documents/publication/wcms_226229.pdf 
ORGANIZAÇÃO DAS NAÇÕES UNIDAS. Resolução Final da Assembleia Geral da ONU. 20 set. 2005, Disponível em:

https://www.unric.org/html/portuguese/summit2005/World\%20Summit\%20OutcomeptREV.pdf

PATUSSI, Roque. Bolivianos em São Paulo: Travessia na De\$ordem Global: Fórum Social das Migrações. São Paulo: Paulinas, 2005. apud ILLES, Paulo; TIMOTEO, Gabrielle Louise Soares and FIORUCCI, Elaine da Silva. Tráfico de Pessoas para fins de exploração do trabalho na cidade de São Paulo. Cad. Pagu [online]. 2008, n.31, pp.199-217. ISSN 01048333. Disponível em: http://www.scielo.br/pdf/cpa/n31/n31a10. Acesso em: 02 ago. 2019.

QUADRA-SALCEDO, Tomás. El recurso de amparo y los derechos fundamentales en las relaciones entre particulares. Madrid: Civitas, 1981, p.70.

SARLET, Ingo Wolfgang. A eficácia dos Direitos Fundamentais. $5^{\text {a }}$ ed., Porto Alegre: Livraria do Advogado, 2005, p. 379.

SILVA, L. A. G. da; BRITTO, C. R. Repensando o conceito do trabalho escravo contemporâneo para a sua erradicação na realidade laboral brasileira. Efetividade dos direitos humanos, culturas jurídicas e movimentos sociais e direito do trabalho e eficácia dos direitos fundamentais no meio ambiente do trabalho. Coord. Alejandro GonzálezVaras Ibáñez, José Claudio Monteiro de Brito Filho, Luciana Aboim Machado Gonçalves da Silva, Maria Aurea Baroni Cecato, Raymundo Juliano Feitosa. Zaragoza, 1 ed., 2019.

SILVA, Luciana Aboim Machado Gonçalves da. A Aplicação dos Direitos Fundamentais aos Estrangeiros Não-Residentes no Brasil. Direito Público, [S.1.], v. 3, n. 14, fev. 2010. ISSN 2236-1766. Disponível em:

https://www.portaldeperiodicos.idp.edu.br/direitopublico/article/view/1409/875. Acesso em: 01 ago. 2019.

TAVARES, André Ramos. Curso de Direito Constitucional. 3. ed. rev. e atual. São Paulo: Saraiva, 2006. p. 436.

TOBLER, C. After "Brexit": will rights acquired in the context of the free movement of persons be protected? A comparative perspective. Revista de Direito Constitucional e Internacional. São Paulo, ano 25, v. 99, p. 362, jan/fev. 2017. 